NASA Technical Memorandum 88269

\title{
Model-Following Control for an Oblique-Wing Aircraft
}

Gurbux S. Alag, Robert W. Kempel, Joseph W. Pahle, John J. Bresina, and Febo Bartoli

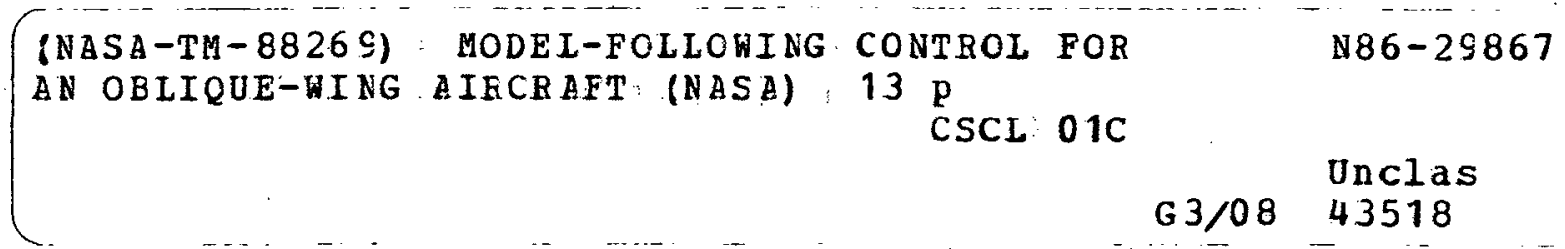

August 1986

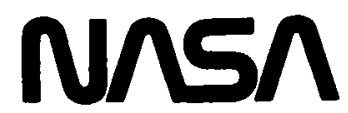


NASA Technical Memorandum 88269

\section{Model-Following Control for an Oblique-Wing Aircraft}

Gurbux S. Alag, Robert W. Kempel, Joseph W. Pahie, John J. Bresina, and Febo Bartoli Ames Research Center, Dryden Flight Research Facility, Edwards, California

\section{N/SA}

National Aeronautics and

Space Administration

Ames Research Center

Dryden Flight Research Facility

Edwards, California 93523-5000 
Gurbux S. Al ag*

Western Michigan University

Kal amazoo, Michigan

\author{
and \\ Robert W. Kempel, ** Joseph W. Pahle, \\ John J. Bresina, $\star \star$ and Febo Bartol $i^{\star \star}$ \\ NASA Ames Research Center \\ Dryden Flight Research Facility \\ Edwards, California
}

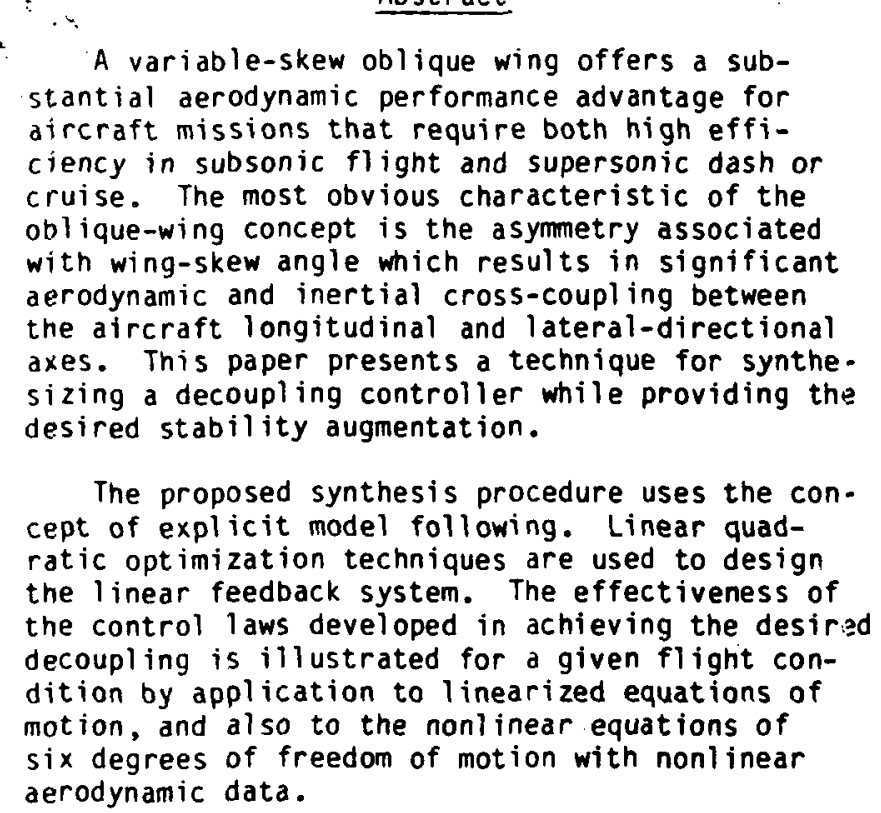

The proposed synthesis procedure uses the concept of explicit model following. Linear quadratic optimization techniques are used to design the linear feedback system. The effectiveness of the control laws developed in achieving the desired decoupling is illustrated for a given flight condition by application to linearized equations of motion, and also to the nonlinear equations of six degrees of freedom of motion with nonlinear aerodynamic data.

\section{Nomencl ature}

$\begin{array}{ll}A, B & \text { system matrices, } \\ h & \text { altitude } \\ J & \text { cost functional } \\ K & \text { gain matrix } \\ M & \text { Mach number } \\ \text { OWRA } & \text { oblique-wing research airc } \\ p & \text { roll rate, deg/sec } \\ Q, D & \text { state weighting matrix } \\ q & \text { pitch rate, deg/sec } \\ R & \text { control weighting matrix } \\ r & \text { yaw rate, deg/sec } \\ S & \text { complex frequency } \\ t & \text { time }\end{array}$

*Associate Professor, Electrical Engineering Dept., Member AIAA.

* Aerospace Engineer.

tAerospace Engineer, Member AIAA.

$\begin{array}{ll}u & \text { input vector } \\ v & \text { velocity, ft/sec } \\ x & \text { state vector } \\ \alpha & \text { angle of attack, deg } \\ B & \text { sideslip angle, deg } \\ \delta & \text { control surface deflection } \\ \theta & \text { pitch angle, deg } \\ \Lambda & \text { wing skew angle, deg } \\ \phi & \text { bank angle, deg } \\ \text { Subscripts } \\ \text { aL } & \text { left aileron } \\ \text { aR } & \text { right aileron } \\ \text { hL } & \text { left horizontal tail } \\ \text { hR } & \text { right norizontal tail } \\ m & \text { model } \\ \text { P } & \text { aircraft } \\ \text { Superscripts }\end{array}$

number of inputs

number of states

matrix transpose

Introduction

The advantages of an oblique wing were first noted in the 1940's. However, not until recently have the interest, technology, and mission of an oblique-wing design evolved into a full-scale flight research program. Dryden Flight Research Facility of NASA Ames Research Center and the U.S. Navy are developing an oblique-wing research aircraft (OWRA). Gregory, I and Wiler and White 2 have outlined potential advantages and disadvantages of this type of airplane. Theoretical and wind tunnel studies have shown that a variableskew oblique wing offers a substantial aerodynamic performance advantage for aircraft missions that require both high efficiency in subsonic flight and supersonic dash or cruise. 
The most obvious disadvantage of the obliquewing concept is the asymmetry associated with wing-skew angle. This asymetry results in significant aerodynamic and inertial cross-coupling between the aircraft longitudinal and lateraldirectional axes.

The test bed for OWRA will be the NASA F -8 digital fly-by-wire aircraft. This aircraft will be modified by the removal of the current high wing and installation of a composite wing-andpivot assembly. A major part of the OWRA program will be the synthesis of a flight control system which will provide acceptable stabilization and decoupling across the Mach, angle-of-attack, and wing-skew envelope. These aircraft stability and decoupling requirements are ideally suited for the application of modern control theory techniques to the solution of problens associated with OWRA.

The potential advantages of the oblique-wing concept can only be realized by development of related technologies. Foremost among these is the control system architecture to compensate for cross-coupled aircraft responses, while presenting the crew with the feel of a coriventional airplane. Current typical design procedures synthesize aircraft controllers bised on solutions of two, or at most, three degries of freedom. However, the added OWRA stabili::ation and decoupling problems require at least "ive degrees of freedom simul taneously.

Model following ha:i been a popular method for the design of multivar able control systems, and shown to be amenable to the solution of many aircraft control problems.. Commencing with the work of Kalman ${ }^{3}$ and Tyler, 4 extensive use has been made of the linear optimal control theory in design of model-following contro:lers. Yor $e^{5}$ used this method for simultaneous stability augmentation and mode decoupling. While optinal control theory provides an extremuly flexiole synthesis technique, various structural approdcnes have been adopted in synthesizin! model-following controllers.6 A controller bilsed on perfect model following (such as perfect. matching of the dynamics of the compensated plant to those of the model) was presented by Alag, Kempel, and Pahle 7 for control of OWRA. Thoughn the desired degree of decoupling was achieved, the control surface activity was excessive and alternate controller development was requi red.

This paper presents the use of models in design of linear feedback systems by means of linear-quadratic optimization. The linear control law developed provides the decoupling as well as the desired stability iugmentation. The effectiveness of the control law is illustrated by time responses from linearized equations of motion, and nonlinear equations of six degrees of freedom of aircraft motion for a siven flight condition.

\section{Model-Foll owing Systems}

\section{Problem Definition}

The concept of model following is useful when an ideal set of plant equations of motion can be specified. The objective of model-following flight control is to force the aircraft to respond as the model would respond to a given pilot command. More precisely, the model-following problem can be stated as follows.

Given the linearized aircraft dynamics,

$$
\dot{x}_{p}=A_{p} x_{p}+B_{p} u_{p}
$$

where $x_{p} \varepsilon R^{n}, u_{p} \varepsilon R^{m}, A_{p}$, and $B_{p}$ are matrices of appropriate dimensions, find the control $u_{p}$ '. such that the aircraft states $x_{p}$ approximate "reasonably well" model state vector $x_{m}$. The model state vector $x_{m}$ is defined by the equation:

$$
\dot{x}_{m}=\dot{A}_{m} x_{m}+B_{m} u_{m}
$$

where $x_{m} \in R^{n}, u_{m} \in R^{m}, A_{m}$, and $B_{m}$ are matrices of appropriate dimensions.

For OWRA, the state and input vectors are given by

$X=\left[\begin{array}{c}v \\ \alpha \\ B \\ \phi \\ \theta \\ p \\ q \\ r\end{array}\right] \begin{aligned} & \text { velocity, ft/sec } \\ & \text { angle-of-attack, deg } \\ & \text { sideslip angle, deg } \\ & \text { bank angle, deg } \\ & \text { pitch angle, deg } \\ & \text { roll rate, deg/sec } \\ & \text { pitch rate, deg/sec } \\ & \text { yaw rate, deg/sec }\end{aligned}$

$u=\left[\begin{array}{l}\delta_{\mathrm{hL}} \\ \delta_{\mathrm{hR}} \\ \delta_{\mathrm{aL}} \\ \delta_{\mathrm{aR}} \\ \delta_{\mathrm{R}}\end{array}\right] \begin{aligned} & \text { left horizontal tail deflection, deg } \\ & \text { right horizontal tail deflection, deg } \\ & \text { left aileron deflection, deg } \\ & \text { right aileron deflection, deg } \\ & \text { rudder deflection, deg }\end{aligned}$

The desired model of the aircraft, defined by matrices $A_{m}$ and $B_{m}$, as well as the aircraft matrices $A_{p}$ and $B_{p}$, are given in Table 1. The desired model used in this study is a modification of the zero-wing-skew configuration at the same flight condition. The aircraft matrices correspond to a flight condition of Mach 0.8 and an altitude of $20,000 \mathrm{ft}$ at $45^{\circ}$ wing skew. The elements of $A_{m}$ were modified to increase the short period and dutch-roll mode damping, and to provide improved roll and spiral mode characteristics.

\section{Explicit Model-Following Systems}

There are two configurations of model following, known as implicit model following and explicit model following. As Fig. l shows, in implicit model following, the control inputs to the plant are formed from the aircraft states and pilot input. No dynamic coupling exists between the model states and the closed-loop plant; the model state $x_{m}$ appears only in the performance index.

Figure 2 illustrates the explicit model following in wich the model states must be generated for use in forming the control input. Explicit model following requires the simulation of the model as a part of feedforward controller. Alignment of plant and model in the presence of 
uncertainties, such as unknown parameters and random disturbances, requires this type of control. This enables a continuous correction of the errors between model and plant states even in the presence of unknown disturbances.

The dynamics of the plant and model are governed by the following linear state equations:

$$
\begin{aligned}
& \dot{x}_{p}=A_{p} x_{p}+B_{p} u_{p} \\
& \dot{x}_{m}=A_{m} x_{m}+B_{m} u_{m}
\end{aligned}
$$

Defining an augmented state vector $x$, the dynamics of the system are expressed as

$$
\dot{x}=A x+B u_{p}
$$

where

$$
x=\left[\begin{array}{l}
x_{p} \\
x_{m} \\
u_{m}
\end{array}\right] \quad A=\left[\begin{array}{ccc}
A_{p} & 0 & 0 \\
0 & A_{n n} & B_{m} \\
0 & 0 & 0
\end{array}\right] \quad B=\left[\begin{array}{l}
B_{p} \\
0 \\
0
\end{array}\right]
$$

The pilot input $u_{m}$ is modeled as a constant, an assumption that does not overly distort the reality of the situation and allows a complete analysis of the problem from a theoretical viewpoint.

In explicit model following, the control function up is required to millimize a performance index given by

$$
J=\frac{1}{2} \int_{0}^{\infty}\left[\left(x_{p}-x_{m}\right)^{\top} Q\left(x_{p}-x_{m}\right)+u_{p}^{\top} R u_{p}\right] d t
$$

where $Q \geq 0, R>0$ are weighting matrices. Using the augmented state vector $x$, the index $J$ can be rewritten as

$$
j=\frac{1}{2} \int_{0}^{\infty}\left(x^{\top} \tilde{Q} x+u_{p}^{\top} R u_{p}\right) d t
$$

where

$$
\tilde{Q}=\left[\begin{array}{rrr}
Q & -Q & 0 \\
-Q & Q & 0 \\
0 & 0 & 0
\end{array}\right]
$$

If pair $(A, B)$ is stabilizable and pair (A,D with $\left.{ }_{D} T_{D}=\tilde{Q}\right)$ detectable, the optimal control up which minimizes $J$ is given by

$$
u_{p}=k_{x}=k_{x p x_{p}}+k_{x m} x_{m}+k_{u m} u_{m}
$$

The model equations must be simulated as a part of the feedforward controller because the controller requires model states.

\section{Results}

The degree of coupling in the open-loop aircraft is illustrated by response to application of a $1^{\circ}$ command input at $1 \mathrm{sec}$ and returned to zero at $3 \mathrm{sec}$ (either by elevator or aileron input). Figure 3 illustrates the open-loop system response of pitch and yaw angular rate and bank angle to an elevator command input. Significant yaw rate and bank angle are generated as a result of pitch command. Of particular interest is the large change in bank angle, indicating a high degree of cross-coupling.

Table 2 gives the gain matrices for the explicit model-following configuration. Figure 4 indicates the linear closed-loop system response for the command input with the explicit modelfollowing gains. The aircraft response is indicated by the solid line, and the model response by the dashed line in figs 3 and 4 . The modelfollowing response is considered satisfactory with considerable attenuation in the degree of coupling, as indicated by the bank angle response of the aircraft. The model response in bank angle is zero. Figure 5 indicates the closed-loop response for the same case but with the aircraft now represented by a nonlinear simulation of 6 degrees of freedom for the same flight condition. The nonlinearities include the constraints on the control surface rate and position.

Figure 6 indicates the response of the openloop system to $1^{\circ}$ aileron command input. Bank angle, yaw angular rate, and pitch angular rate are shown. The relative pitch coupling is not as severe for this case as the roll coupling is for the elevator command; however, coupling is still evident.

Figure 7 indicates the linear closed-loop system response to the same aileron command. A dashed line denotes the model response, and a solid line, the aircraft response. The relatively small coupling in the pitch axis was not considered severe, as indicated by the aircraft pitch-angular rate response. The model pitchangular rate response was zero. The objective in this case was to provide adequate lateraldirectional dynamics. Figure 8 shows the closedloop response for the same case with aircraft nonlinear simulation.

\section{Conclusions}

The method presented describes a decoupled control for a highly coupled unsymmetric aircraft. The method develops an explicit model-following control law by means of linear quadratic optimization techniques. The results indicate that the method does obtain the decoupling. incorporated in the ideal model for the flight condition considered.

Evaluation of the control system on nonlinear equations of six degrees of freedom of motion for the flight condition considered shows promising results for implementation as a candidate control system for the aircraft. Work is in progress to investigate gain scheduling requirements and to obtain piloted simulation results.

\section{References}

1Gregory, T., "Oblique Wing Ready for Research Aircraft," Aerospace America, June 1985, pp. 78-81.

2wiler, C.D. and White, S.N., "Projected Advantage of an Oblique Wing Design on a Fleet Air Defense 
Mission," J. Aircraft, Vol. 22, №. 10, Oct. 1985 , pp. 896-900.

3Kalman, R.E., Englar, T.S., and Bucy, R.S., "Fundamental Study of Adaptive Control Systems," ASD-TR-61-27, Vol. II, 1962, Martin Co., Rias Division, Baltimore, Md.

4Tyler, J.S., "The Characteristics of ModelFollowing Systems as Synthesized by Optimal Control," IEEE Transactions on Automatic Control, Vol. AC-8, Oct. 1964 .
5Yore, E., "Optimal Decoupling Control," 9th Joint Automatic Control Conference of the American Automatic Control Council, New York, 1968, pp. 327-336.

6Morrow, L.D. and Bal asubramanian, R., "Real Model Following Control," J. Aircraft, Vol. 12, No. 12 , Dec. 1975, pp. 996-998.

7Alag, G.S., Kempel, R.W., and Pahle, J.W., "Decoupling Control Synthesis for an Oblique-Wing Aircraft," NASA TM-86801, 1986.

TABLE 1. - AIRCRAFT AND MODEL MATRICES*

(a) Aircraft matrices

\begin{tabular}{|c|c|c|c|c|c|c|c|c|}
\hline$A_{p}=$ & {$\left[\begin{array}{r}0.009 t \\
-0.0001 \\
0.0001 \\
0.0001 \\
0.0000 \\
0.0000 \\
-0.000: \\
0.00011\end{array}\right.$} & $\begin{array}{r}22.0707 \\
-0.7826 \\
-0.0592 \\
0.0000 \\
0.0000 \\
33.1432 \\
-8.6816 \\
-1.0092\end{array}$ & $\begin{array}{r}10.5479 \\
0.0958 \\
-0.2908 \\
0.0000 \\
0.0000 \\
-53.6933 \\
0.7975 \\
10.7521\end{array}$ & $\begin{array}{r}-0.1341 \\
0.0000 \\
0.0387 \\
0.0000 \\
0.0000 \\
0.0000 \\
0.0000 \\
0.0000\end{array}$ & $\begin{array}{r}-32.1127 \\
0.0000 \\
-0.0002 \\
0.0000 \\
0.0000 \\
0.0000 \\
0.0000 \\
0.0000\end{array}$ & $\begin{array}{r}0.0057 \\
0.0030 \\
0.0259 \\
1.0000 \\
0.0000 \\
-3.1250 \\
0.1679 \\
-0.0213\end{array}$ & $\begin{array}{r}-0.0005 \\
0.9926 \\
0.0001 \\
0.0000 \\
1.0000 \\
2.0552 \\
-1.0352 \\
0.0080\end{array}$ & $\left.\begin{array}{r}-0.0265 \\
-0.0003 \\
-0.9920 \\
0.0247 \\
0.0000 \\
1.7210 \\
0.1810 \\
-0.7129\end{array}\right]$ \\
\hline$B_{p}=$ & {$\left[\begin{array}{r}0.0844 \\
-0.0971 \\
-0.0161 \\
0.0000 \\
0.00011 \\
12.9804 \\
-9.4073 \\
1.9854\end{array}\right.$} & $\begin{array}{r}-0.0309 \\
-0.0974 \\
0.0166 \\
0.0000 \\
0.0000 \\
-22.2654 \\
-10.8655 \\
-2.2579\end{array}$ & $\begin{array}{r}-0.2210 \\
-0.0198 \\
0.0008 \\
0.0000 \\
0.0000 \\
15.8467 \\
-1.2311 \\
0.5262\end{array}$ & $\begin{array}{r}-1.2572 \\
-0.0302 \\
-0.0005 \\
0.0000 \\
0.0000 \\
-11.8422 \\
0.8797 \\
-0.3276\end{array}$ & $\left.\begin{array}{r}3.6598 \\
0.0000 \\
0.0647 \\
0.0000 \\
0.0000 \\
13.2774 \\
0.5694 \\
-6.2493\end{array}\right]$ & & & \\
\hline
\end{tabular}

(b) Model matrices

\begin{tabular}{|c|c|c|c|c|c|c|c|c|}
\hline$A_{m}=$ & {$\left[\begin{array}{c}-0.007 \\
-0.000 . \\
0.0000 \\
0.0000 \\
0.0000 \\
0.0000 \\
0.000 \\
0.0000\end{array}\right.$} & $\begin{array}{r}23.5906 \\
-1.1052 \\
0.0900 \\
0.0000 \\
0.0000 \\
0.0000 \\
-12.1514 \\
0.0000\end{array}$ & $\begin{array}{r}0.0000 \\
0.0000 \\
-0.2852 \\
.0 .0000 \\
0.0000 \\
-44.3777 \\
0.0000 \\
12.1943\end{array}$ & $\begin{array}{l}0.0000 \\
0.0000 \\
0.9387 \\
0.0000 \\
0.0000 \\
0.0000 \\
0.0000 \\
0.0000\end{array}$ & $\begin{array}{r}-32.1129 \\
0.0000 \\
0.0000 \\
0.0000 \\
0.0000 \\
0.0000 \\
0.0000 \\
0.0000\end{array}$ & $\begin{array}{r}0.0000 \\
0.0000 \\
-0.0148 \\
1.0000 \\
0.0000 \\
-4.5000 \\
0.0000 \\
0.0000\end{array}$ & $\begin{array}{r}0.0000 \\
0.9909 \\
0.0000 \\
0.0000 \\
1.0000 \\
0.0000 \\
-4.0000 \\
0.1890\end{array}$ & $\begin{array}{r}0.0000 \\
0.0000 \\
-0.9919 \\
-0.0120 \\
0.0000 \\
14.6000 \\
0.0000 \\
-4.0000\end{array}$ \\
\hline$B_{m}=$ & {$\left[\begin{array}{r}-2.203 i \\
-0.08413 \\
-0.0161 \\
0.0000 \\
0.0001 \\
11.237 ! \\
-7.822 ! \\
0.0001\end{array}\right.$} & $\begin{array}{r}-2.2232 \\
-0.0848 \\
0.0156 \\
0.0000 \\
0.0000 \\
-11.2379 \\
-7.8229 \\
0.0000\end{array}$ & $\begin{array}{r}-0.8354 \\
-0.0494 \\
0.0000 \\
0.0000 \\
0.0000 \\
29.0513 \\
0.0000 \\
0.0000\end{array}$ & $\begin{array}{r}-0.8354 \\
-0.0494 \\
0.0000 \\
0.0000 \\
0.0000 \\
-29.0513 \\
0.0000 \\
0.0000\end{array}$ & $\left.\begin{array}{r}0.0000 \\
0.0000 \\
0.0647 \\
0.0000 \\
0.0000 \\
9.6847 \\
0.0000 \\
-6.6502\end{array}\right]$ & & & . \\
\hline
\end{tabular}

$\star M=0.8 ; h=20,000 \mathrm{ft} ; \alpha_{0}=1.6^{\circ} ; \Lambda=45^{\circ}$ 
TABLE 2. - GAIN MATRICES*

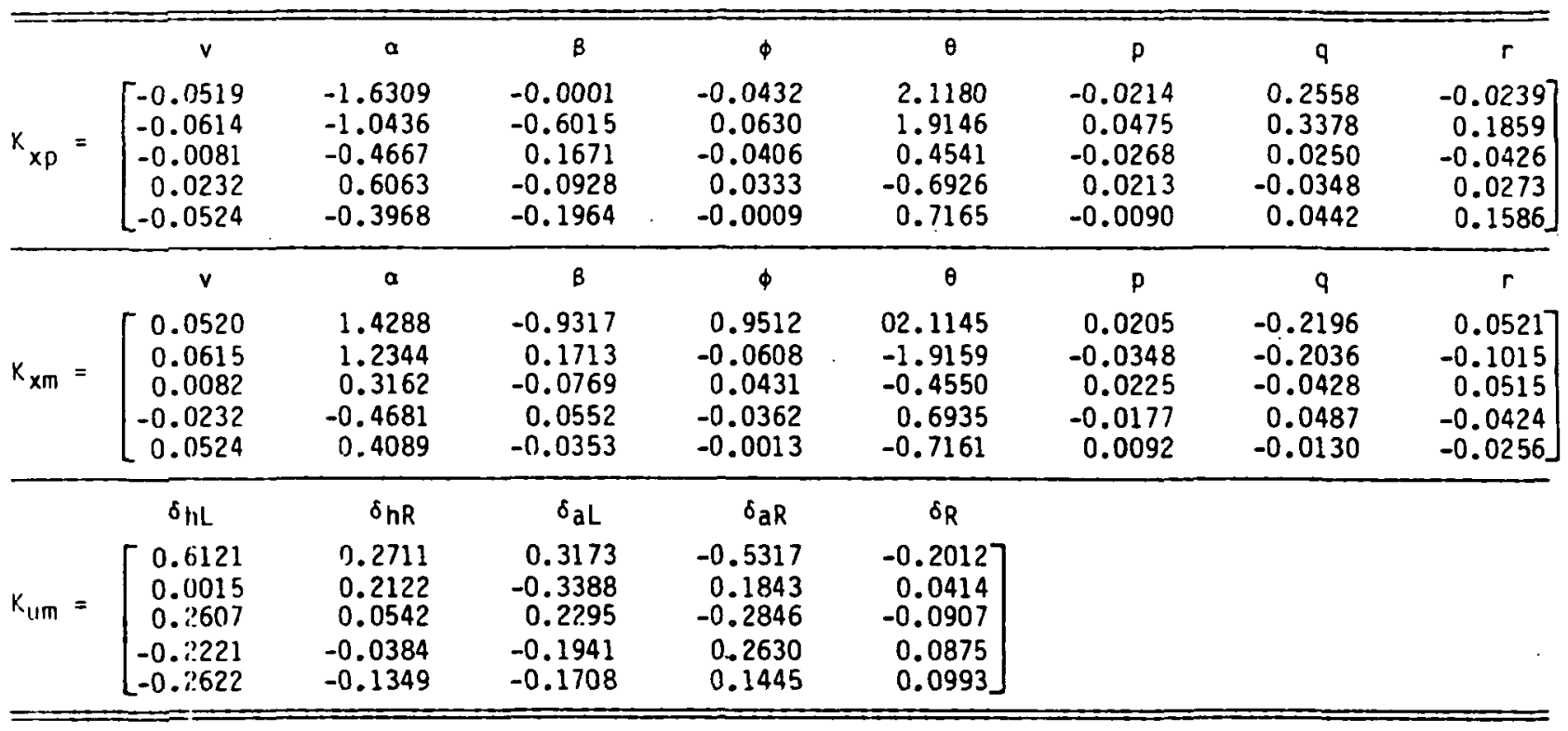

$\star M=0.8 ; h=20,000 \mathrm{ft} ; \Lambda=45^{\circ}$

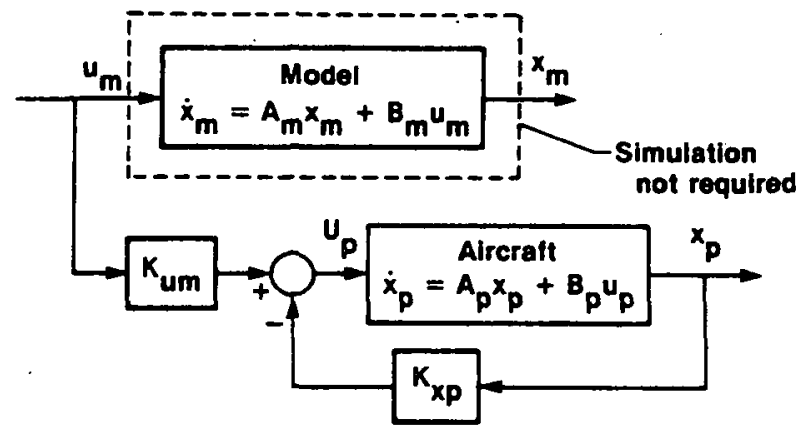

Fig. 1 Implicit model-following control law st sucture.

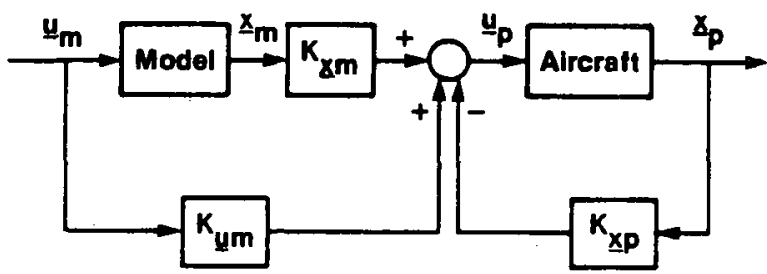

Fig. 2 Explicit model-following control law structure. 


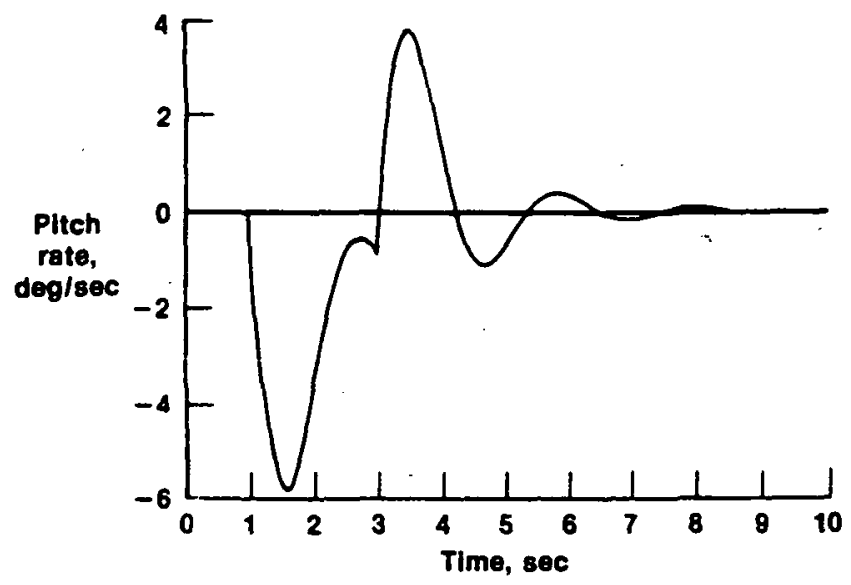

(a) Pitch rate.

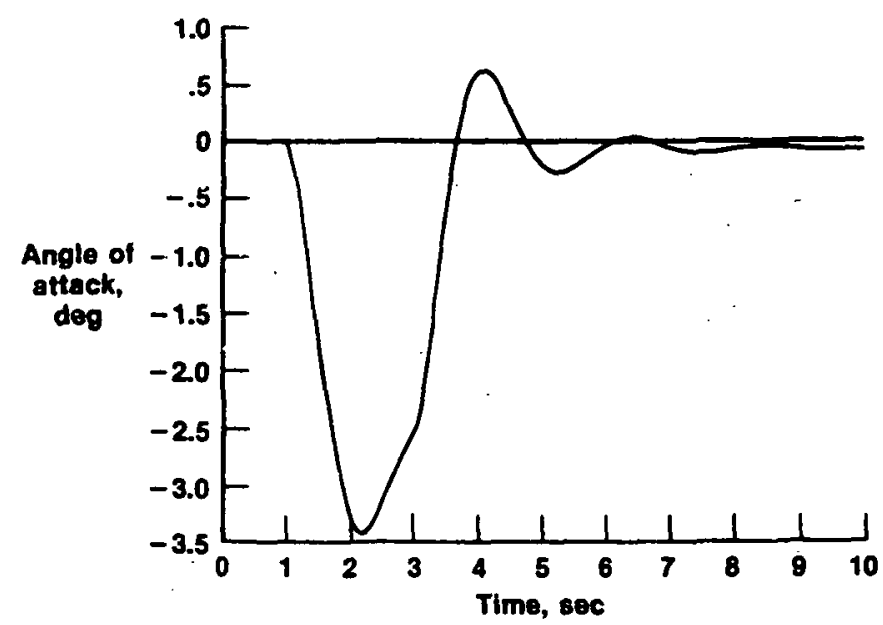

(b) Angle of attaok.

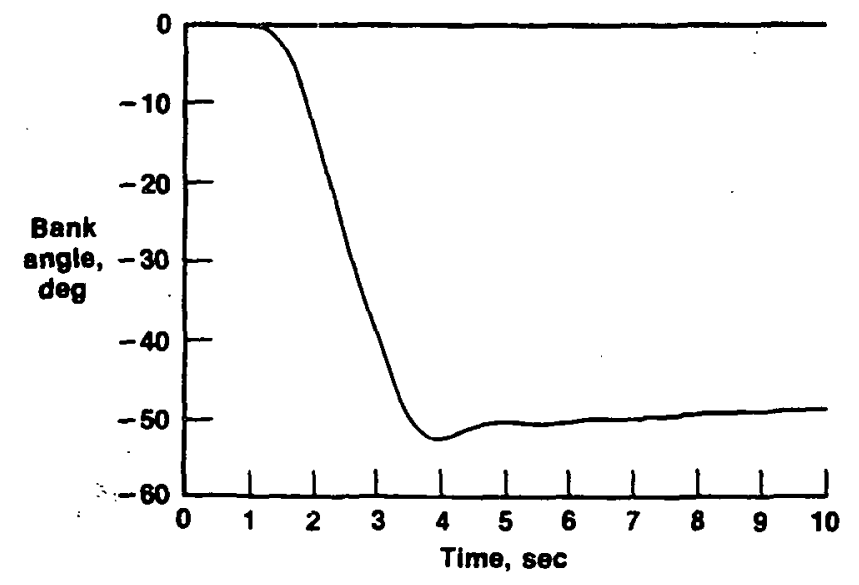

(c) Bank angle.

Fig. 3 Open-loop airoraft response to elevator command input. 


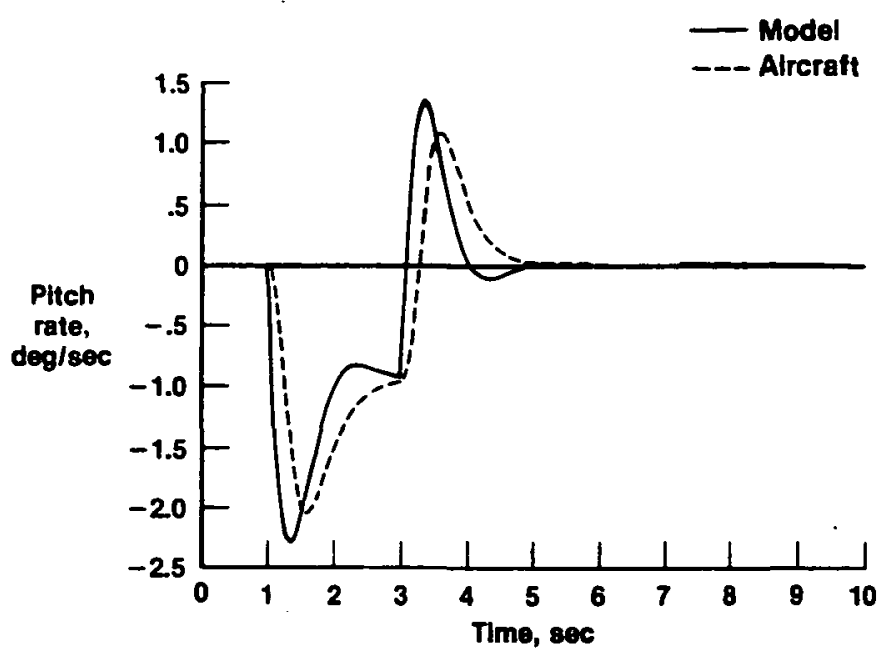

(a) Pitch rate.

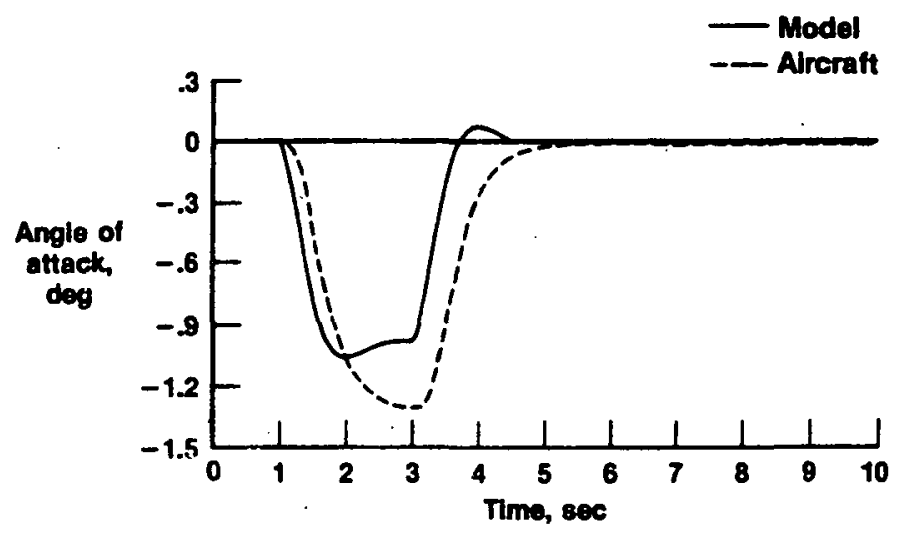

(b) Angle of attack.

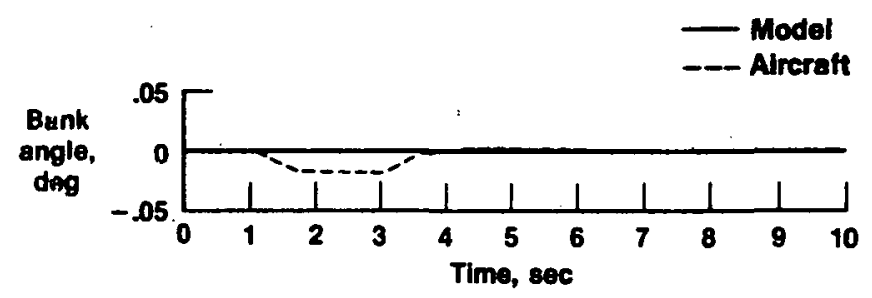

(c) Bank angle.

Fig. I Model-following response to elevator command input. 

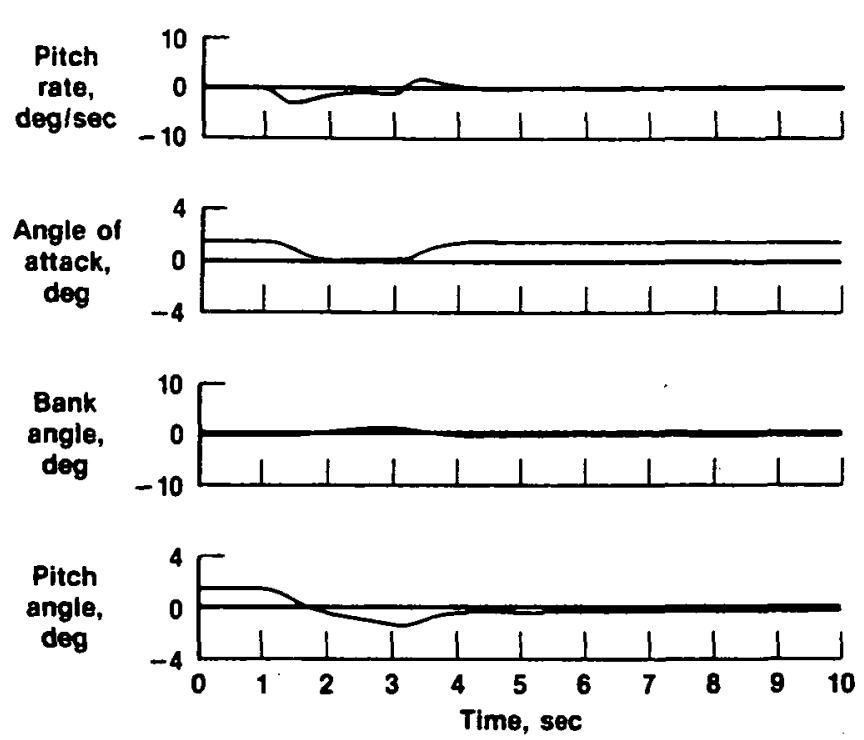

Fig. 5 Nonlinear model-following response to elevator command input.

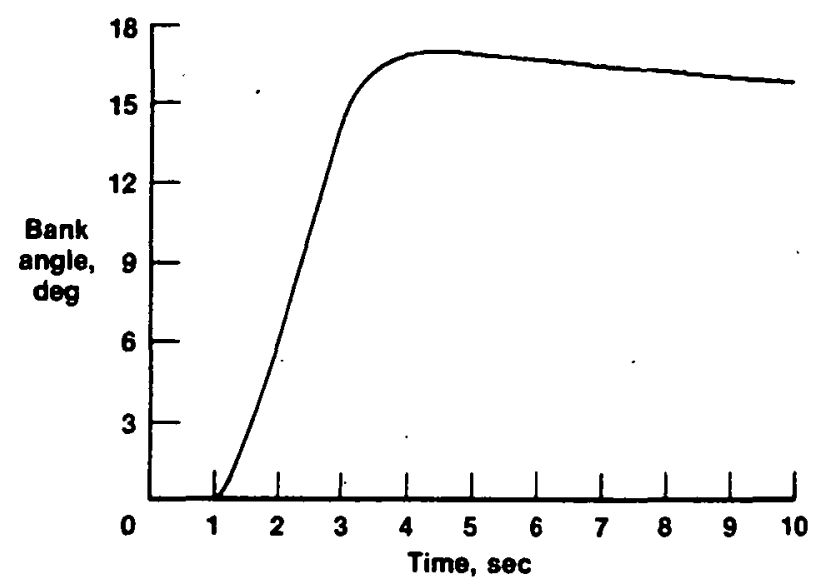

(a) Bank angle.

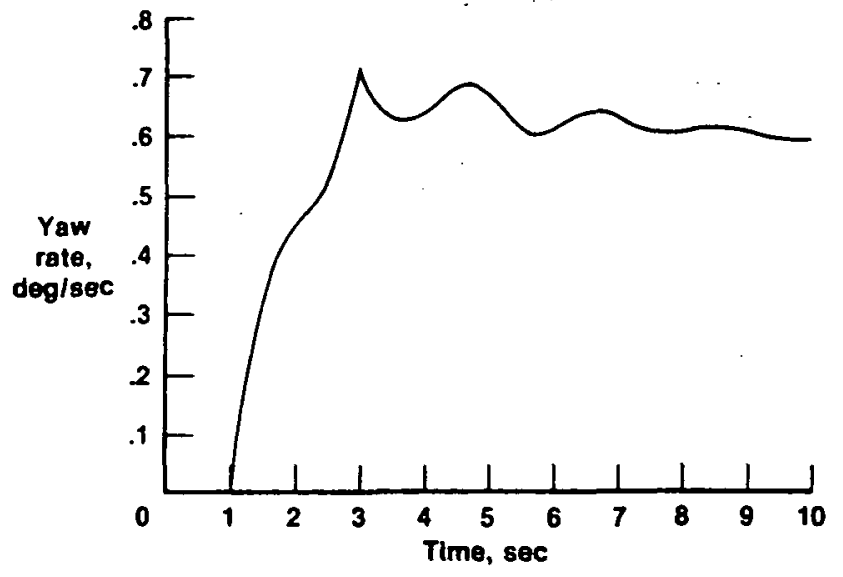

(b) Yaw rate.

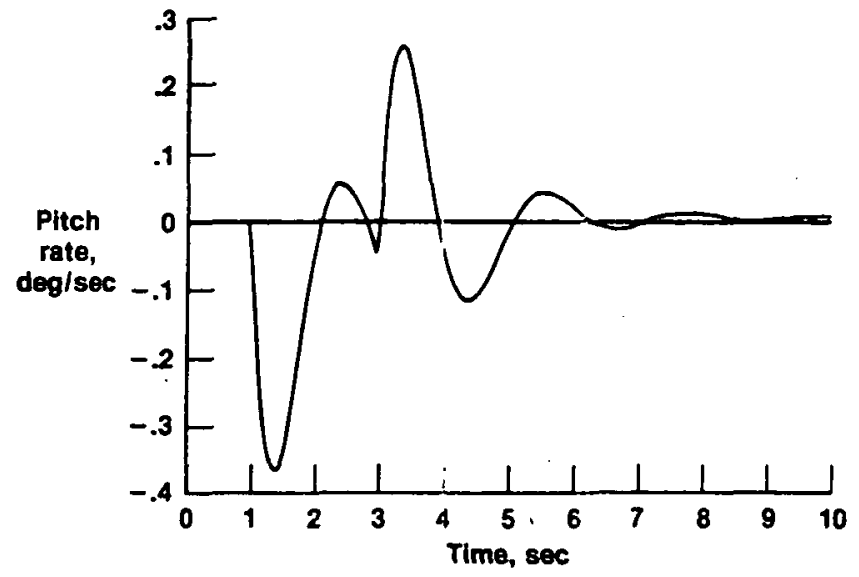

(c) Pitch rate.

Fig. 6 Open-loop aircraft response to aileron command input. 


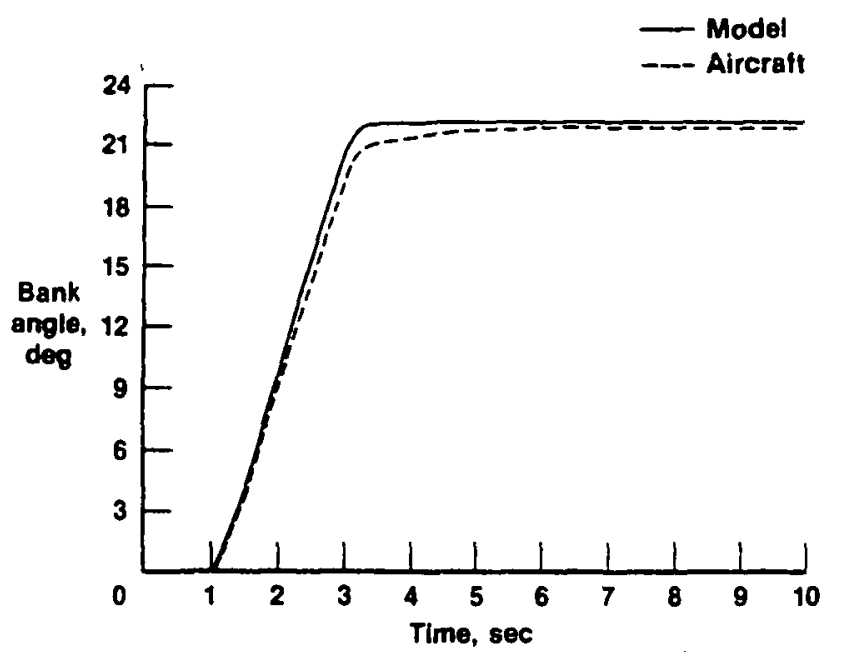

(a) Bank angle.

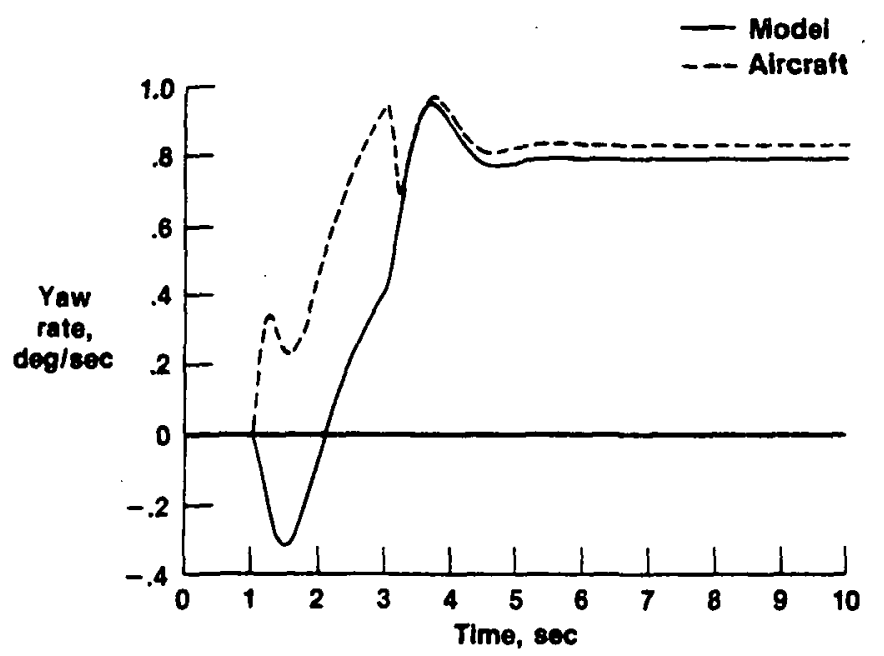

(b) Yaw rate.

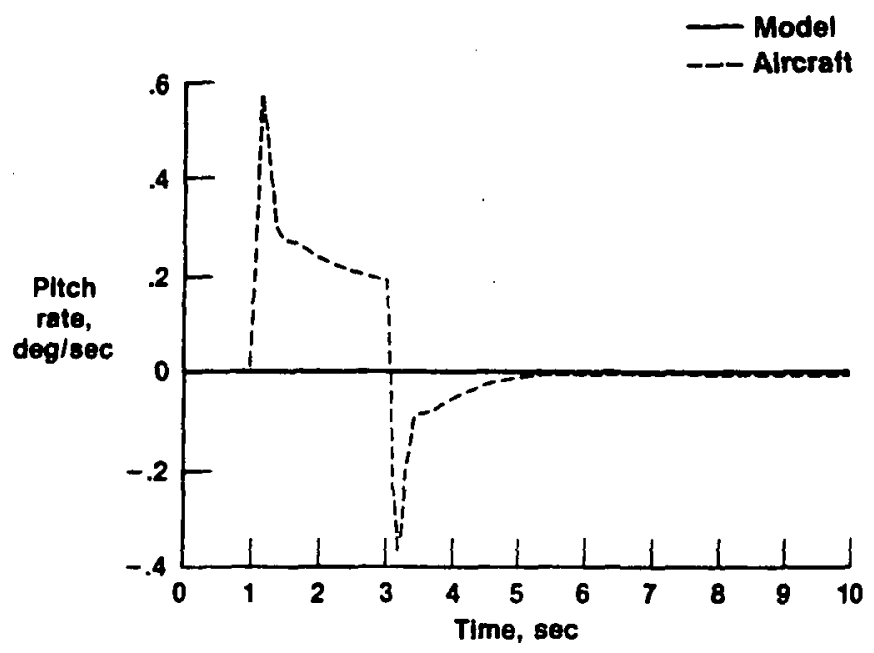

(c) Pitch rate.

Fig. 7 Model-following response to aileron command input. 

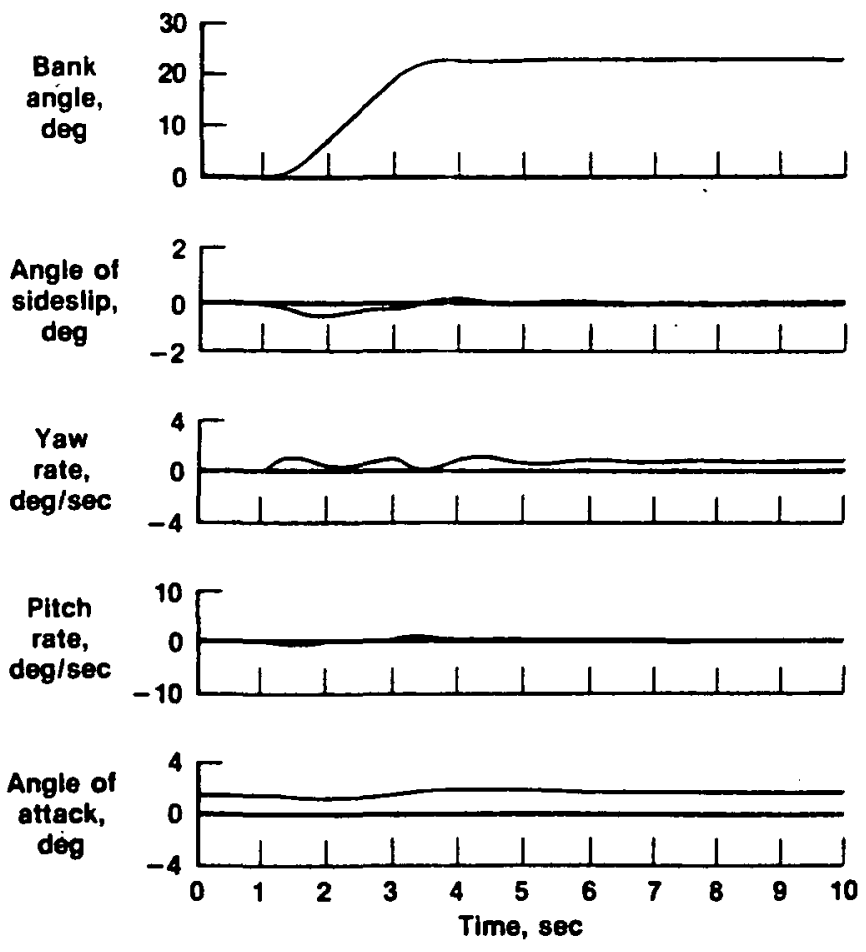

Fig. 8 Nonlinear model-following response to aileron command. 


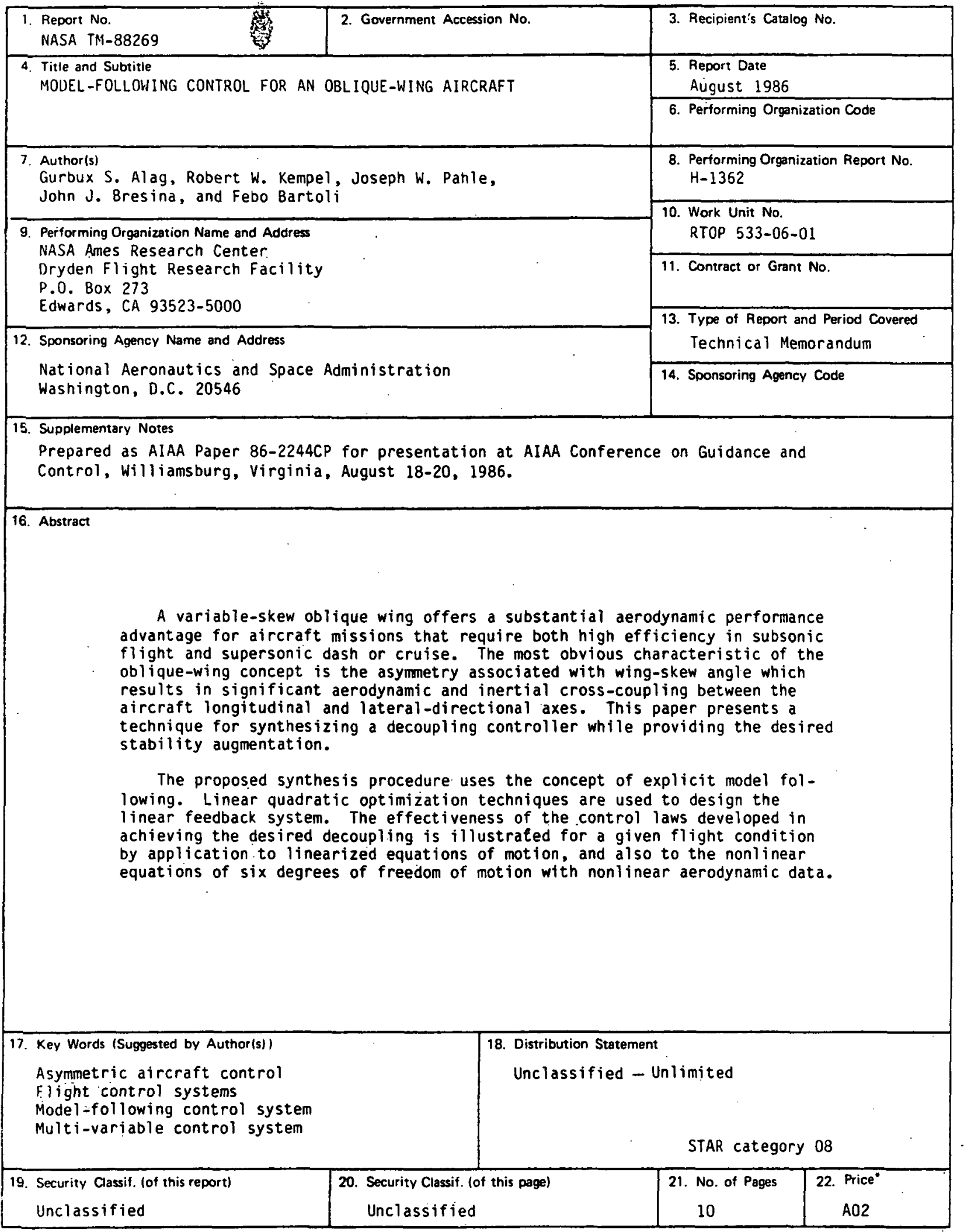

"For sale by the National Technical Information Service, Springfield, virginia 22161. 